\title{
Leadership, Beliefs and Coordination: An Explorative Discussion
}

\author{
Nicolai J. Foss \\ LINK \\ Department of Industrial Economics and Strategy \\ Copenhagen Business School \\ Howitzvej 60 \\ 2000 Frederiksberg \\ Denmark \\ njf.ivs@cbs.dk
}

$5^{\text {th }}$ revision, 28 April 2000

\begin{abstract}
Although recent economics contributions represent important strides forward in the understanding of leadership behavior, the cognitive and symbolic dimensions of the phenomenon have attracted virtually no interests from economists and game theorists. I argue that an understanding of these dimensions may be founded on coordination games, particularly to the extent that these illustrate interactive belief formation. In this context, leadership is defined as the taking of actions that coordinate the complementary actions of many people through the creation of belief conditions that (at least) substitute for common knowledge, and where these actions characteristically consists of some act of communication directed at those being led. The concept of common knowledge (or, its approximation by means of notions of common belief) is argued to be particularly important to understanding leadership. Thus, leaders may establish common knowledge conditions, and assist the coordination of strategies in this way, or make decisions in situations where coordination problems persist in spite of common knowledge.
\end{abstract}

\section{Acknowledgments}

Comments on earlier version of this paper from Kirsten Foss, Reinoud Joosten, Thorbjörn Knudsen, Klaus Meyer, George Richardson, Ulrich Witt, participants at seminars at HEC, Paris; the Max Planck Institut, Jena, and Copenhagen Business School, and three anonymous reviewers of this journal are gratefully acknowledged. In particular, I am grateful to the reviewers for challenging, insightful and most useful comments, and for pointing out errors in an earlier draft. Of course, all remaining errors, obscurities, etc. are entirely my responsibility. 


\section{Introduction}

Why are major organizational restructurings often communicated through largescale gatherings where top-management addresses employees through face-to-face contact instead of relying on, for example, electronic mail? Why do many corporations spend substantial amounts of money on flying in managers from foreign subsidiaries to tell them things in personal meetings with top-management that they could easily be told over the telephone, fax or e-mail? More generally, why are executives so fond of face-to-face, verbal communication, when in many situations written communication or others means of communication would appear to be relevant substitutes? ${ }^{1}$

The described phenomena may seem to be ritualistic and ceremonial, perhaps only given to explanation in terms of group-psychology or the desire to achieve legitimacy through conforming to institutional requirements, etc. For such reasons, it may be argued that they lie outside the orbit of "rational" social science. However, it will be argued in this paper that simple ideas from (mostly) game theory suggest a rational explanation. More specifically, the hypothesis here is that the above phenomena are manifestations of the exercise of leadership designed to coordinate the complementary actions of many people through the creation of belief conditions that (at least) approximate common knowledge. ${ }^{2}$ Indeed, the overall argument is that leadership, coordination, and common beliefs/knowledge are closely related phenomena, and that leadership is a prominent member of the set of "alternative institutions for resolving coordination problems" (Cooper, DeJong, Forsythe and Ross 1994). The argument is developed using simple ideas from noncooperative game theory on coordination games, and on exploring these ideas from a decision-theoretic point of view; hence, the emphasis on the epistemic states of players.

As an academic subject, leadership is characterized by huge differences with respect to the basic conceptualization of the phenomenon. No doubt this is because many disciplines have contributed to the study of leadership and because leadership behavior is manifest in many diverse social settings. It is therefore advisable to be explicit about what is meant by leadership. And the literature on leadership has in general heeded such advise: Even a casual reading of the literature reveals that it is very rich indeed with respect to providing

\footnotetext{
1 A phenomenon that has been noted repeatedly in the literature on executive behavior at least since Carlsson (1951).

2 An event is common knowledge among a group of players if each player knows it, each one knows that the other players know it, each player knows that other players know that the other players know it and so on. For splendid non-technical discussions of common knowledge, see Geanakoplos (1992) and Bicchieri (1993). Common knowledge was introduced by Lewis (1969) and formalized by Aumann (1976). The link between firm organization and common knowledge is stressed by Cremer (1990).
} 
conceptualizations. ${ }^{3}$ In fact, it is much richer in this respect than with respect to providing explanations of the phenomenon.

In this paper I define leadership as the ability to resolve coordination problems by influencing beliefs. This is both a conceptualization and a stab at an explanation. For some reason, the leader is able to spot and resolve coordination problems by influencing beliefs more effectively than other people. For example, the leader may have priviliged information about some state of nature that perturbs the underlying game. Because, as will often be the case in practice, the leader's own pay-offs are somehow tied to the pay-offs of his followers (and they know this), they are actually prepared to believe and follow him. The leader's announcement of what strategy should be followed is effective in resolving the underlying coordination problem because it creates a belief structure that at least approximates common knowledge. It is well-known from the literatures on conventions, focal points, the robustness of game theoretical equilibria, etc. that whether common knowledge obtains or not may, the extent to which it is approximated by beliefs, etc. may make crucial differences for outcomes (e.g., Rubinstein 1989; Monderer and Samet 1989; Crawford and Haller 1990).

This overall explanation arguably grasps much - if certainly not all - of what is meant by leadership, both in common parlance and in the scholarly literature. Because the emphasis is on the coordination of beliefs (e.g., of people in an organization), it is appropriate to make use of a particular class of games, namely coordination games. Indeed, the paper may be read as a contribution to a small but growing literature that tries to cast organizational phenomena in terms of resolving interaction problems that can be represented by various types of coordination games (notably Camerer and Knez 1994, 1996, 1997; Greenan and Guellec 1994; Weber 1998). ${ }^{4}$ However, this literature has not dealt with leadership. Another important source of inspiration is political science contributions on leadership (notably, Calvert 1992, 1995; Frohlich, Oppenheimer and Young 1971; Hardin 1982) which clearly identifies a link between leadership and coordination problems (particularly Calvert 1992), but without using the epistemic arguments presented in this paper.

The design of the paper is the following. First comes a rather selective literature review. Instead of reviewing the enormous and diverse literature on leadership, I concentrate briefly on the few economics approaches to leadership. I then argue that a different approach to leadership may be developed - one that both retains a rational choice orientation and links up with those contributions to the leadership literature that has stressed the cognitive aspects of leadership, that

\footnotetext{
${ }^{3}$ House and Baetz' (1979) early survey listed over 70 definitions of leadership, and Rost (1991) lists 221 different definitions.

4 On a broader level, it links up with the general expansion of interest in coordination games during the last decade or so (e.g., Van Huyck, Battalio, and Beil 1990, 1991; Bicchieri 1993; Colman 1997; Colman and Bacharach 1998; Cooper and John 1988; Cooper 1999; Cooper, DeJong, Forsythe and Ross 1992, 1994; Crawford and Haller 1990; Galesloot and Goyal 1997; Kramarz 1996; Sugden 1995).
} 
is, how leaders influence what people believe. I then continue with presenting some basic game theory ideas. Even on an elementary level we can make the basic point that coordination games aren't trivial, somewhat contrary to common perception, and that they are likely to capture the essence of a large number of realworld situations. Notably, they are likely to help us gain an improved understanding of important aspects of leadership. What is offered in the following pages is not a finely honed theory about leadership behavior (as in Hermalin 1998). Rather, it is an explorative discussion (somewhat in the style of Kreps 1990a and Langlois 1998), aiming at convinving organizational scholars of the value of basic game theoretic ideas and economists of organization of the possibility of alternative routes of research.

\section{Leadership: A (Very) Partial Literature Review}

Webster's dictionary defines leadership as "leading others along a way, guiding." There are clearly two distinct aspects involved in the exercise of leadership, namely, first, selecting a goal, and, second, making others follow that goal (Gardner 1990: 11). From the perspective of the economics of organization, "... the problem of motivating employees to follow a vision is the standard agency problem" (Brickley, Smith and Zimmerman 1996: 309). In the following, I shall briefly discuss a few contributions that work out of a similar logic, and then suggest the possibility of an alternative view that while it is consistent with a rational choice approach puts more stress on cognition and belief formation than on motivation per se.

\section{Some Recent Economics Contributions}

That social interaction problems and leadership are somehow connected is not a new recognition in social science research per se. At least, political scientists have often made the link explicit (Calvert 1992, 1995; Frohlich, Oppenheimer and Young 1971; Hardin 1982). In contrast, economists have had relatively little to say about leadership, and when they have addressed the issue, it fair to say that one specific modeling heuristic has been dominant. To see this, consider three important economics contributions to the leadership literature, namely Kreps (1990), Rotemberg and Saloner (1993) and Hermalin (1998). All three work out of contract economics approaches. Thus, Kreps and Rotemberg and Saloner begin from an incomplete contract setting, whereas Hermalin takes his starting point in the Holmström (1982) (complete contracts) team-model. Consider each one of these in turn.

Strictly speaking, Kreps' paper is not about leadership per se, but rather about corporate culture, and how the reputation that a corporate culture may help build provides an important part of the explanation of firm organization. Nevertheless, it certainly makes provision for leadership. Beginning from the property rights/incomplete contracts theory (Grossman and Hart 1986; Hart 1995), Kreps argues that incompleteness of contracts may produce a need for implicit contracts. 
However, in the face of unforeseen contingencies, it is not clear how implicit contracts should be administered; in particular, it is not clear how well standard reputation arguments work with unforeseen contingencies. The possible role of leadership in this setting is to provide general principles (i.e., focal points) that instructs employees and suppliers about how unforeseen contingencies will be handled in the future by management (see also Shleifer and Summers 1990).

Rotemberg and Saloner are more taken up with how leadership styles are influenced by environmental contingencies. However, the same basic insights as in Kreps - namely, that the provision of incentives is not straightforward under incomplete contracting - plays a key role in their paper. Specifically, they consider the problem of compensating middle managers who develop project ideas, when compensation cannot be based on the manager's unobservable effort but has to be based on whether the project is implemented, and where the CEO may have difficulties committing to implementation; hence, contracting is incomplete and commitment is imperfect. Leadership style affects employees' beliefs about how they will be compensated in various circumstances. Assuming that shareholders will select the firm's leadership style to maximize profits, they will appoint "empathic" leaders (whose utility functions include the utility of their manager) if the firm operates in an opportunity-rich environment, whereas "selfish" leaders (whose utility functions do include the utility of their managers) will be appointed in stable environments.

Finally, Hermalin studies incentive problems in the context of the team model of Holmström (1982). The problem here is that the leader for some reason has privileged information about what the team should do, but — because she shares in team output - has an incentive to exaggerate the value of effort devoted to the common activity. In Hermalin's main case the problem may be solved if the leader acts as a Stackelberg leader and expends effort earlier than the other team members. Based on their observation of effort, the other team members form beliefs about the leader's information. Interestingly, this produces the conclusion that the leader works harder than she would do under symmetric information. The leader indeed "leads by example."

To be sure, these modeling efforts are neat, logical and produce interesting, sometimes counterintuitive, conclusions. However, they are limited in various ways that are typical of recent contract economics. The basic thrust of this literature is to conceptualize virtually any issue related to economic organization in terms of solving incentive-conflicts. ${ }^{5}$ The motivation for this presumably is an underlying argument that in the absence of such conflicts, the first-best can be reached without

\footnotetext{
5 "Any" should be taken quite literally (see Langlois and Foss 1999 for some examples). Although some contract theorists note that there are other problems of economic organization than incentive conflicts, little more than lip service is normally being paid to these problems (the exception being the team theory literature, cf. Radner 1986). For example, although Milgrom and Roberts (1992: 114 ) point out that "[t]he key role of management in organization is to ensure coordination," and their book stand out as offering comparatively much attention to coordination issues, its main thrust nevertheless is on incentive issues.
} 
major obstacles (e.g., Hart 1995). Thus, the essence of the above contributions is that (business) leaders exist because they resolve incentive conflicts, albeit sophisticated and non-standard ones. However, other perspectives on leadership are certainly possible, and insights from related disciplines are likely to enrichen economic approaches to leadership. ${ }^{6}$

\section{Towards a Different View}

The view that all, or most, organizational phenomena are reducible to problems of aligning incentives is one that is implicitly (and sometimes explicitly) contradicted by contributions to organization studies (Thompson 1967), the executive and leadership literature (Barnard 1948; Carlsson 1951; Kotter 1996; Selznick 1957), political science (Calvert 1992, 1995), (rational choice) sociology (Coleman 1990), and in some quarters of the economics of organization (Camerer and Knez 1994, 1996, 1997; Langlois 1998; Langlois and Foss 1999; Milgrom and Roberts 1992: chapter 4; Weber 1998). Many of these contributions are directly relevant to the issue of leadership.

For example, Coleman (1990) observes that charismatic authority may be a response to coordination problems that don't necessarily turn on misaligned incentives (see also Langlois 1998). In fact, Coleman's discussion suggests that he has an assurance game in mind.7 Camerer and Knez $(1994,1996,1997)$ and Calvert (1992, 1995) argue that attention should be shifted to coordination games (rather than cooperation games) in seeking a foundation for the understanding of organizational phenomena. Although he has placed primary emphasis on problems of ex post opportunism, Williamson (1991: 278) has not been blind to the possibility of coordination problems, noting that failures of coordination "... may arise because autonomous parties read and react to signals differently, even though their purpose is to achieve a timely and compatible combined response." While making much room for the role of incentives in organization, Chester Barnard also emphasized the importance of "the inculcation of belief in the real existence of a common purpose", which he considered to be "an essential executive

\footnotetext{
${ }^{6}$ In fact, in a recent contribution, political scientist Gary Miller (1992) urges economists of organization to take a closer look at what political scientists have to say about leadership. This is because much of the literature on political economy may serve both as an important bridge between the behavioral and the economics views of hierarchy and as a source of new insights. In spite of this, Miller's own treatment is strikingly economistic. Thus, he only discusses leadership in the context of the incentive conflict problems that are the main focus of interest in the mainstream economics literature on organization.

7 An assurance (or, "stag-hunt") game may be exemplified by the following game: There are $n$ players that have to choose among 2 strategies, Risky and Safe. Safe yields some fixed pay-off y $\in$ $(0,1)$, whereas Risky yields 1 if at least $\rho$ players choose it and 0 otherwise. This game has two Nash equilibria in pure strategies (all choose Risky and all choose Safe). An generalization of assurance games is represented by weak-link or minimum effort coordination games, in which, for example, a group choose numbers and the group pay-off depends on the lowest number selected by any player. See Van Huyck, Battalio and Beil (1990) for a classic experimental study of weakestlink games, Camerer and Knez (1994) for an application of such games to the "expectational assets" and Weber (1998) for an application to firm growth.
} 
function" (Barnard 1948: 87). Indeed, he very clearly argued that an "... an organization can secure the efforts necessary to its existence ... either by the objective inducements it provides or by changing states of mind" (idem.: 141; my emphasis).

The aim of the following pages is to develop some of these suggestions. Thus, in line with Camerer and Knez (1994, 1996, 1997), Weber (1998) and Calvert $(1992,1995)$, the focus is on coordination games rather than on cooperation games. And in line with Barnard, and others who have stressed the cognitive aspects of leadership (e.g., Selznick 1957), the emphasis will be on "the inculcation of belief" and on "changing states of mind," for example, through (credible) communication. In contrast, all incentive problems will be suppressed. Basic game theory ideas will be used to explicate the reasoning.

\section{Coordination Problems and Coordination Games}

\section{Cooperation and Coordination Games}

Criticism of the predominant incentive-alignment heuristic in the economics of organization has often been cast in terms of basic game theory (e.g., Camerer and Knez 1994, 1996, 1997; Foss 1996). Thus, the critics have argued that all emphasis has been on cooperation games, that is, games where the pay-off space of the game is such that the efficient outcomes are not supportable as equilibria (at least in one-shot play). The key problem that such a game leads one to ponder is how to avoid the Pareto-inferior outcome. Indeed, the basic hold-up situation has a prisoners' dilemma structure (Milgrom and Roberts 1992: 128), and this is also the case with the team production problem and other problems with information externalities and moral hazard (Holmström 1982, 1999). Accordingly, the literature is taken up with how re-allocating incentives and property rights may improve on outcomes. In contrast, the economics of organization literature is characterized by a corresponding lack of interest in the interaction problems that may be represented by coordination games - a somewhat surprising neglect given the the increasing emphasis on such problems in other areas of economics, such as standards (Farrell and Saloner 1985; Witt 1997), conventions (Young 1996), learning behavior (Crawford and Haller 1990), and macroeconomics (Cooper 1999) (Friedman 1994). ${ }^{8}$

Conventionally, there is a distinction between shared interest (or "pure") coordination games and coordination games with mixed interests. In the former category, players' preferences over equilibria coincide. In symmetric shared interest coordination games, all equilibria are efficient and pay-off equivalent, so that players are indifferent about which equilibrium is chosen, as long as one is in fact chosen. The coordination problem in question concerns actually choosing an equilibrium (Bicchieri 1993). In contrast, non-symmetric shared interests

\footnotetext{
8 Thanks to an anonymous reviewer for stressing this.
} 
coordination games, exhibit multiple Pareto-ranked equilibria. This (sub-) category encompasses assurance games where the coordination problem is caused by the riskiness of coordination on the Pareto optimal equilibrium (Cooper 1999). While coordination games with mixed interests will also exhibit multiple equilibria, these equilibria are ranked differently by the players (cf. the battle of the sexes or the chicken games), so that the problem again is choosing one of the equilibria. In the present paper, reference will mostly be to shared interest coordination games. ${ }^{9}$

\section{Coordination Problems and Approaches to Organizational Phenomena}

Much recent work in game theory has consisted in refining a number of equilibrium concepts, most of them variations on the basic notion of Nash equilibrium. In general, the refinement literature analyzes alternative equilibrium concepts in terms of the epistemic states of players, that is, what they know or believe about other players's beliefs, knowledge, rationality, etc., and about the game (Aumann and Brandenburger 1995). Thus, the literature has a strong decision-theoretic, even "subjectivist,"10 orientation. Complicated interactive epistemics is involved, and impressive reasoning skills are imputed to players. Critics may easily gain the impression that classical game theory solves the coordination problem by defining it away, that is to say, by assuming that agents by means of pure ratiocination can reason their way to equilibrium.11 And such critics may argue that the literature begins from what is basically an existence claim, namely that if rational players have commonly known and identical beliefs about all other players' strategies, then those beliefs are consistent with some equilibrium in the game. A problem with this is that nothing is said about the origin and formation of beliefs, and it is in principle possible that although there is an equilibrium in players' strategies, they may never be able to realize that equilibrium. ${ }^{12}$

Along the lines of classical game theory, most of today's formal economics of organization proceeds on the assumption that players can choose the efficient gameform for regulating their trade and can also choose any desired equilibrium thereof. ${ }^{13}$ It is a story of unproblematic coordination, given the constraints.

\footnotetext{
9 This is certainly not to say that leadership is irrelevant to the problem of selecting equilibria in mixed-motives games. Howeever, for the purposes of this paper, it is not necessary to go into these games.

10 Thus, much of the basic thrust of the literature is reminiscent of Hayek (1937) and Richardson (1960) - seminal contributions that ought to be recognized as important, early contributions to game theory.

11 The exception to this rationalistic approach is, of course, constituted by evolutionary game theory.

12 Clearly, simply proceeding by eliminating equilibria by means of various refinement procedures will not do; we still need to rationalize the emergence of beliefs that can sustain the final equilibrium.

13 This is the case of the standard principal-agent type analysis of compensation schemes (Salanié 1997), for the analysis of implicit contracts in long-term relationships, and also for the incomplete
} 
Although information asymmetries and conflicting incentives may hinder reaching the first-best outcome, there is no problem picking the equilibrium that is induced by these constraints (and the rationality of the players, etc.). In this literature, one does not encounter, say, two pay-off equivalent second-best outcomes, with players confronting the coordination problem of choosing between the two. Such problem are defined away. Of course, this is a shortcut to conceptualizing various contractual arrangements as equilibria of some properly specified underlying games, involving conflicting incentives, and it may be argued that suppressing coordination problems is justified because it allows to concentrate on the essentials (but see Foss and Foss 2000). Moreover, it may be claimed that coordination problems are in fact not suppressed in the formal economics of organization, since the whole point of these exercises is to show how agents may coordinate to avoid inefficiency, or at least reach the second best. However, something different is involved here. More specifically, the argument is that organizations, and leaders, do more than making agents avoid inefficiencies in prisoners' dilemma-like interaction situations. For example, a proponent of institutional organization theory may argue that a function of organization is to define what strategies are available, in the sense of being "legitimate" relative to some environment (Powell and DiMaggio 1991). An entrepreneurship scholar may point out that the function of leadership is to alert to be new business opportunities. Although placing primary emphasis on the hold-up problem, Williamson $(1985,1996,1998)$ has long argued - following a time-honoured tradition in organization theory (March and Simon 1958) - that an organization also serves the purpose of alleviating bounds on rationality.

To be sure, it is hard to make game-theoretic sense of such functions of organization and leadership. For example, if the leader's function lie in his "defining new strategies," this amounts to introducing a new game, and it is not at all clear what is gained by comparing a string of different games. However, more unconventional ideas (relative to economics) on "symbolic leadership", the leader's "the inculcation of belief" among those being led, etc. can in fact be treated in relatively simple game-theoretic terms. Camerer and Knez $(1994,1996,1997)$ and Weber (1998) have already demonstrated the usefulness of a coordination game perspective for understanding a host of organizational phenomena. The following may be taken as an extension of the basic thrust of their arguments to the phenomenon of leadership in organizations. To understand the argument, it is, however, necessary to spend some time arguing that, somewhat contrary to common perception, coordination games are non-trivial and quite fundamental.

\section{Coordination Games are Non-Trivial and Fundamental}

The dominant implicit attitude among social scientists appears, at least until recently, to have been that coordination games, particularly of the shared interests

contract type of concern with the sharing of joint surplus and how this influences the choice of ownership arrangements (Grossman and Hart 1986). 
type, are basically trivial. ${ }^{14}$ The sources of this attitude are hard to trace, but the verdict issued in R. Duncan Luce and Howard Raiffa's (1957: 59) very influential book, Games and Decisions that at least in pure coordination games "everything is trivial" seems to be a possible - and likely - source. In contrast to what may be called "the Luce and Raiffa legacy", a growing litterature asserts that coordination games, even pure ones, are not so trivial as they may appear at first glance. Moreover, they are fundamental in the sense that they help identify fundamental interaction problems (e.g., interactive belief formation) and how such problems are resolved (e.g., through conventions). Finally, coordination games are fundamental, not only in the sense that a host of everyday situations conform to their structure(s) (Schelling 1960, 1978), but also in the sense that from a theoretical perspective, problems of equilibrium selection, which may often be seen as coordination problems, are very common. ${ }^{15}$

Fundamentally, coordination games are (very often) non-trivial, because their multiplicity of equilibria serves to highlight the importance for outcomes of agents' beliefs about each others' beliefs. ${ }^{16}$ And such interactive epistemology can be quite complicated business, as both the philosophical (Lewis 1969; Dupuy 1989; Bicchieri 1993; Gilbert 1992), theoretical (Rubinstein 1989; Bacharach 1993; Aumann and Brandenburger 1995; Sugden 1995; Colman 1998; Colman and Bacharach 1998) and experimental (Cooper et al. 1992, 1994; Bacharach and Bernasconi 1997; Colman and Stirk 1998) literatures confirm. Thus, equilibrium selection theories have been devised for rationalizing certain outcomes rather than others in asymmetric coordination games (Harsanyi and Selten 1988); there is a body of work on how repeated play may lead to the convergence to an equilibrium (Crawford and Haller 1990); work has been done on how players' labelling of their strategies influence their beliefs (Sugden 1995); and there is a literature on communication in coordination games (Farrell 1987; Rabin 1990) — all of which is far from being trivial.

Moreover, coordination games are fundamental in a number of ways, first of all, in the basic phenomenological sense of being pervasive in social life (Schelling 1960, 1978). Second, they provide a useful conceptualization of one class of interaction situations that may lead to the emergence of social institutions (Calvert 1995; Young 1996) or organizational phenomena (Camerer and Knez 1994, 1996, 1997). Moreover, they are fundamental in a theoretical sense, too, since recent

\footnotetext{
${ }_{14}$ In contrast, philosophers have taken an interest for a long time (Lewis 1969; Gilbert 1992).

15 Calvert (1995) makes similar points and concludes that "... a well-developed theory of coordination games is necessary ... to help us understand the emergence or design of institutions, and the conduct and maintenance of nearly any institution to foster cooperative behavior" (p.243).

16 This does not mean that issues of belief dynamics, etc. are necessarily neglected in cooperation games, namely if these are repeated. However, belief dynamics certainly are neglected in the conventional one-shot games with standard preferences, since no beliefs will lead to cooperation. (Thanks to an anonymous reviewer for this point). One may perhaps say that the basic question in cooperation games rather has to do with preferences (do players like to cooperate? Is this particular player a "sucker" or will he defect? Etc. (cf. Camerer and Knez 1996).
} 
work in game theory has revealed that coordination problems (that may be represented in terms of coordination games) emerge in a multiplicity of game situations. In particular, this is the case as dynamics is introduced, the number of players is increased, and less knowledge is ascribed to players.

\section{Types of Coordination Problems}

A possible categorization of coordination problems that may be illustrated by means of coordination games lies is the following distinction between three broad classes of coordination problems:

1) the problem of coordinating on an equilibrium when agents are initially outside equilibrium (i.e., have inconsistent beliefs, lack of common knowledge), and don't know, for example, how strategegies are labelled;

2) the problem of coordinating on one equilibrium out of a multitude, when strategies, pay-offs, and rationality are common knowledge (e.g., the battle of the sexes game); and

3) the problem of moving from an inferior equilibrium to the efficient equilibrium, when strategies, pay-offs, and rationality are common knowledge (e.g., the assurance game). ${ }^{17}$

What is common to all these three problems is that belief dynamics is essential to them. They are briefly considered seriatim.

Coordinating on an equilibrium. This is the problem of rationalizing the formation of those beliefs that will make it possible for agents to realize some equilibrium. To be sure, there has been an increasing interest in defining equilibria in terms of the beliefs and conjectures of agents, for example, in connection with interpreting the notion of mixed strategies (where the relevant probabilities are interpreted as subjectively held probabilities) (Aumann and Brandenburger 1995). However, the problem of actually rationalizing the emergence of equilibrium beliefs - rather than "simply" providing conditions for these - has attracted less general interest, 18 as least until recently. ${ }^{19}$

Thus, in a much-cited paper, Crawford and Haller (1990) study how fully strategic agents may learn to coordinate in the context of a repeated coordination game where they initially have no shared information about how the strategies are

\footnotetext{
17 The main difference between 2) and 3) is that, first, in 3) the players are supposed to somehow have got stuck in the inferior equilibrium whereas in 2) they haven't commenced play, and, second, that 3) rules out pay-off equivalent equilibria.

${ }^{18}$ For example, in Aumann and Brandenburger's (1995) reformulation of the epistemic conditions for Nash equilibrium, players are assumed to know the conjectures of other players. As Mailath (1998: 1351n) observes, this assumption "... does not appear to be a significant improvement over the original assumption of Nash behavior."

19 Of course, various evolutionary and semi-evolutionary approaches which portray players as adjusting stage-game strategies across iterations as responses to the observed behavior of other players have been around for a long time. However, the present paper does not consider this body of work, because of the rationalist orientation of the paper.
} 
labeled or how the game is presented (e.g., the normal form of the game) and where strategies are symmetric (i.e., yield the same pay-offs) and where the players are also symmetric in the sense that they are in identical strategic positions in the game. Although they are playing the same game, they may (and likely, will) perceive it differently. This effectively excludes any focal points based on the description of the game. However, after some play, the players will develop distinctions between strategies and players, and when these distinctions become common knowledge, coordination may take place very quickly. The assumption that puts in motion, as it were, the right belief dynamics that establishes common knowledge is that players follow the meta-strategy of repeating successful strategies.

Of course, one should be extremely cautious in drawing inferences from the very simplified setting of Crawford and Haller (1990) to more complicated (and realistic) settings, where the problem of reaching an equilibrium may be complicated by, for example, the imperfection as guides to future behavior of precedents generated in earlier play when players play against different other players (Knez 1998). However, one important feature of the Crawford and Haller analysis lies in their demonstration that in the situations they analyze, " ... it is sometimes optimal to forsake an efficient strategy forever in favor of an inefficient one that is less costly to locate" (1990: 584). In other words, although coordination sometimes take place quickly, there is no guarantee that agents coordinate in an efficient manner.

Selecting among multiple equilibria. It is well-known that prisoners' dilemma games with many players or hidden information imply many different ways of motivating cooperation, and that a key problem is making players choose beliefs that will pick out one of these solutions (Calvert 1995: 242). However, somewhat in contrast to the situation analyzed in Crawford and Haller (1990), there may be a coordination problem, even in the presence of common knowledge. The conventional illustration of this is the symmetric pure coordination game, such as game 1a in Figure 1.

\section{XXXXXXXX Insert Figure 1 here XXXXXXXX}

The problem is that classical game theory is not terribly helpful with respect to telling us how players will avoid coordination failure in such situations. Of course, when a (one-shot) game has multiple Nash equilibria in pure strategies, it often has a unique mixed strategy equilibrium (Nash 1951). But the basic problem of rationalizing the beliefs that lead players to play mixed strategies, and choose certain probabilities (and believe that others choose certain probabilities) rather than other ones is not really addressed. There is still a fundamental problem of rationalizing the formation of equilibrating beliefs. In one interpretation of Nash equilibrium - namely, that it is the outcome of non-binding preplay communication leading to the selection of a self-enforcing agreement (Farrell 1987) - the problem can, of course, be handled. It is arguably outside the conventional interpretation of games in normal form, such as the one in matrix 1, where the 
players make their choices simultaneously and there is no explicitly modeled stage in which they can communicate. However, in an exploratory paper such as the present one, we wish to allow for this possibility, too.

Moving away from an inferior equilibrium. The simultaneous move assurance game (matrix 1b) has become a popular pedagogical device for illustrating coordination failures, and it is one of the work horses of the experimental game theorist (e.g., van Huyck et al. 1990; Cooper et al. 1988, 1992). Of course, this is motivated by the game's ability to portray risky coordination and strategic complementarity. Relatedly, the game connects to the theoretical issue of equilibrium selection in situations in which the existing refinement procedures do not work. For example, Harsanyi and Selten (1988) forcefully argue that the payoff dominant outcome $((2,2)$ in matrix $1 b)$ is a natural focal point. However, there is experimental evidence that coordination failure "almost always" occur (in the absence of pre-play communication) (van Huyck et al. 1990; Cooper et al. 1992).

Perhaps less obviously, rationalizing the pay-off dominant outcome as the focal point in the apparently less risky asymmetric pure coordination game (matrix 1c) is far from trivial (Farrell 1988; Colman 1997; Colman and Bacharach 1997). The basic problem is that $\mathrm{A}$ appears to have no rational grounds for choosing the 2 strategy in lieu of grounds for believing that B will choose the 2 strategy, because if A would choose the 1 strategy, B would do better by also choosing the 1 strategy. Of course, B is in the same epistemic situation, and the reasoning process winds up in infinite regress. Pre-play communication does not necessarily help, for how can one player be sure that the other player understood him? There still seems to be a problem of justifying beliefs. So how can we justify everybody's strong intuition that the pay-off dominant outcome will in fact be chosen?

In a recent paper, Colman and Bacharach (1997) suggest that players may solve the problem by using something they call the "Stackelberg heuristic". Essentially, this heuristic works by letting agents mentally transform a normal form game to an extensive form game. Thus, they know that they will choose simultaneously but think as if they will choose sequentially. Specifically, player A will simulate the game by thinking of himself as moving first. Then $\mathrm{B}$ has to move with knowledge of A's choice, choosing a best reply meta-strategy, namely strategy 1 if A also chooses 1 and strategy 2 if A also chooses 2 . Of course, the latter choice is best for A. Having performed this simulation, A, returning to the real game, chooses what is (in the mental simulation) the utility maximizing strategy provided that B responds with a best reply (namely strategy 2). Player B, performing the same simulation makes the same choice. However, the requirement for the Stackelberg heuristic to do its work is that these simulations are common knowledge, in other words, that the heuristic itself is common knowledge.

\section{Summing Up and Looking Ahead}

The preceding pages have established that coordination games are non-trivial and fundamental. They are extremely helpful mental laboratories that assist in 
exploring the boundaries of game theory (e.g., Harsanyi and Selten 1988; Colman and Bacharach 1997; Young 1996), and for providing indirect rationales for phenomena, such as conventions (Lewis 1969; Young 1996) and other social phenomena that somehow turns on the issue of belief dynamics. The suggestion that will be developed in the following pages is that coordination games are also helpful for understanding the cognitive aspects of leadership, that is, what Barnard (1938) referred to as "the inculcation of belief in the real existence of a common purpose." 20 The argument is not different in kind from other arguments pertaining to how coordination problems are solved in reality, namely through the effect on the beliefs that players hold of communication, the formation of conventions, etc. ${ }^{21}$ Thus, leadership is an important member of the set of "alternative institutions for resolving coordination problems" (Cooper, DeJong, Forsythe and Ross 1994). However, the argument is, if one likes, "comparative-institutional," in the sense that it is claimed that leadership may, in certain situations, be a low-cost alternative to these other methods of coordination.

\section{Leadership}

\section{Conceptualizing Leadership}

In much of the organization theory literature, it is held that the essence of organization is coordinated response to volatility, for example, in technologies or preferences (Thompson 1967; Galbraith 1973). Obviously, management and leadership have key roles here, for some volatility cannot be handled by organizational routine but requires judgment and decision. As we have seen, the economics of organization, to the extent that it relates to leadership and management issues, is not taken up with managers' and leaders' concrete actions and the judgments that inform such actions. ${ }^{22}$ However, it surely is informative with respect to the leader and manager's roles in the design of explicit and implicit contracts (Kreps 1990a; Miller 1992; Rotemberg and Saloner 1993; Hermalin 1998), and much of the nature of leadership and managerial work may be conceptualized in this way. Thus, a classic contribution on the nature of managerial work (Mintzberg 1973: 5) lists six

... basic reasons why organizations need managers: 1 . The prime purpose of the manager is to ensure that his organization serves its basic purpose ... 2. The manager must design and maintain the stability of his organization's operations ... 3. The manager must take charge of his organization's strategy-making system, and therein adapt his

\footnotetext{
${ }^{20}$ I shall neglect various problems of weakness of will, the control of procastination, etc. as bases for understanding leadership and management (these are treated by, for example, Rumelt 1995).

${ }^{21}$ Notably, Camerer and Knez (1996) suggested that TQM programs (and per implication other management fads) may derive much of their effect from their functioning as focal points.

22 In the words of Loasby (1995: 474), it does not tell us "... how Jones should decide what to do at nine o'clock on Monday morning."
} 
organization in a controlled way to its changing environment ... 4. The manager must ensure that his organization serves the ends of those persons who control it ... 5. The manager must serve as the key informational link between his organization and its environment ... 6 . As formal authority, the manager is responsible for the operating of his organization's status system.

On the face of it, much of this sounds largely consistent with the basic thrust of the economics of organization: It is indeed possible to cast virtually all of the above six points in terms of monitoring and the design of implicit and explicit contracts.

However, if one reads Mintzberg's own further detailing of what the six points actually mean and imply, it turns out that an economics of organization conceptualization does not do full justice to them. For Mintzberg is clear that the production of "values" and "atmosphere" through "directing", disseminating information, and acting as "spokesman", "negotiator", and "figurehead" are what lies behind the above managerial roles. Such roles and functions have so far not been treated from the perspective of the mainstream economics of organization.

The symbolic and cognitive aspects that Mintzberg associate with management become even more pronounced if one turns to the large and diverse literature on leadership in organizations (e.g., Vecchio 1997; Conger and Canungo 1998). Here, the leader is seen as engaging in numerous activities, such as planning strategy, changing standard practice, creating vision and meaning for the organization, and inducing changes in values, attitudes and behavior. The reason why the economics literature on leadership may look somewhat meager (if considerably more precise) relative to the richness in the leadership literature arguably turns on the difficulty of providing economic interpretations of the cognitive and entrepreneurial aspects of leadership in particular. Of course, the aim should not be to present the phenomenon in all its complexity, but it is hard to escape the conclusion that economic approaches to leadership miss some essential aspects of the phenomenon, particularly those relating the the cognitive dimensions.

In the following, I shall suggest that the basic ideas on coordination games that have been discussed so far are helpful for understanding precisely those aspects of leadership. More specifically, I shall develop a notion of leadership as the taking of actions that coordinate the complementary actions of many people through the creation of knowledge (or belief) conditions that at least approximate common knowledge, and where these actions characteristically consists of some act of communication directed at those being led.

\section{Beliefs and Coordination Problems}

An example of the type of belief dynamics that I am taken up with here involves the crucial epistemic construction in H.C. Andersen's well-known fairy tale, "The Emperor's New Clothes" that knowledge hold may be held identically (i.e., everybody knows that $x$ is the case), but not in common. The child's loud 
announcement that the emperor really isn't wearing any clothes creates the belief dynamics that transforms the situation from one in which everybody knows that the emperor is not wearing any clothes to the situation in which everybody knows this and knows that everybody else knows it. The transformation essentially works because something else is common knowledge, namely that everybody knows that everybody knows what the child exclaimed.

One, possibly farfetched, interpretation of the situation described in the tale is that a sort of assurance game is involved: Everybody would prefer that the truth be told, but because pay-offs (and possibly also rationality) are not common knowledge, telling the truth is risky (scorn may be heaped upon you!). Only the "mediation" of the non-calculative child allows for beliefs to be coordinated on the superior equilibrium. In his classic contribution, Schelling (1960) explicitly linked what he called "mediators" to coordination problems:

... a mediator can do more than simply constrain communications putting limits on the order of offers, counter-offers, and so forth - since he can invent contextual material of his own and make potent suggestions. That is, he can influence ... expectations on his own initiative ... When there is no apparent point for agreement, he can create one by his power to make a dramatic suggestion.

In other words, when "Schelling competence" - that is, players' capacity to coordinate by means of focal points (Bacharach and Bernasconi 1997: 2) — is low coordination by means of a "dramatic suggestion" may be required. Although Schelling doesn't spell this out, we may suggest that the creation of common knowledge conditions is what is involved in his notion of mediation. A first hint, then, derived from Andersen and Schelling, is that part of the leader's function may be the break-up of an epistemic stalemate through acts of communication that influence "in the right way" the beliefs held by players. ${ }^{23}$

\section{Coordination and Communication}

The formalization (Crawford and Sobel 1982; Farrell 1988; Rabin 1990) and empirical investigation (Cooper et al. 1989, 1992, 1994) of communication is a relatively recent undertaking in game theoy. Thus, Cooper et al. (1992) experimentally evaluated the effect of "cheap talk" under one-way communication and under two-way communication in the context of an assurance game. They found that with no communication, coordination failure was universal (the efficient equilibrium was never reached), with one-way communication

\footnotetext{
23 This is akin to Farrell's (1988) discussion of pre-play communication in connection with coordination games, and his introduction of a "speaker," that is, an agent who "... can make a suggestion about what players should do in the second stage [after communication]. A suggestion is a list specifying, for each player $i$, a non-empty subset $T_{i}$ of $i$ 's (mixed) strategy space $S_{i}$. We can interpret this as a 'speech' proposing (precisely or vaguely) how everyone should behave in $G$ [the second stage game]. If this speech is credible, we want to assume that everyone believes it; this is the link between words and action" (p.210-11).
} 
coordination substantially improved (the efficient equilibrium was reached about $50 \%$ of the times), and two-way communication almost completely eliminated any coordination failures.

Intuitively, things are even simpler in pure, symmetric coordination games (Rabin 1990), where one would expect one-way communication to be more successful than in the context of assurance games. Thus, one person's communicative act may create a focal point that becomes common knowledge, such as the child's announcement in the H.C. Andersen fairy tale. But there is an apparent difficulty here (Monderer and Samet 1989). For whereas it was implicitly assumed in the discussion above that a public announcement automatically becomes common knowledge, it is not at all obvious that such an assumption is always warranted, particularly as the group to which a message is directed grows in size. For example, there may be a probability, however small, that somebody in the group was absent-minded at the time of the announcement, which effectively means that the announced message will not be common knowledge.

In a famous note, Rubinstein (1989) pointed out that whether or not common knowledge obtains may matter dramatically for outcomes. In his "electronic mail game" example, nature chooses one of two two-person, risky coordination games with equal probabilities. If the state of nature is common knowledge, coordinating on the desired equilibrium is taken by Rubinstein to be straightforward. Not so if what Rubinstein calls "almost common knowledge" obtains, that is, if only a finite (but possibly very large) number of propositions of the sort " 1 knows that 2 knows that A knows ... that the state $x$ (a or b) obtains" are true. Effectively, this situation implies that the game becomes one of incomplete information, although the players are allowed to communicate.

In the example, the first player knows which one of the two games will be played and he sends a message to the second player, informing him about this. The second player acknowledges receipt of the message, player 1 acknowledges receipt of the acknowledgment, and so on. However, there is a small probability that a message gets lost in the process, in which case the process of communication is brought to a halt. The problem now is that neither of the players know whether it was his message or the other player's acknowledgment that was lost. Rubinstein proves that the uncertainty caused by incomplete information implies that under almost common knowledge, there is actually only one Nash equilibrium in the game. Thus, there is no "convergence" to the common knowledge situation, where the players will play a certain strategy if state a obtains and the other strategy if state $b$ obtains. Clearly, the agents would have been better of if some mechanism could somehow throw a condition of common knowledge into their game.

It is of course easy to construct an argument that because we, strictly speaking, can never be absolutely certain that something is common knowledge, many potential Pareto improvements are never realized. Some may even argue that common knowledge is a useless fiction. However, in a stimulating paper Monderer and Samet (1989) argued that common knowledge can be approximated (in a way they make precise) by the notion of common belief. Using Aumann's 
(1976) model, in which knowledge is partitions and beliefs are posterior probabilities, belief may be defined as being "common" in the conventional way, namely when an infinite hierarchy obtains. The difference is that beliefs are held with a probability, such that a common $\rho$-belief may be defined for each $\rho$ in $[0,1]$. Monderer and Samet then show that when $\rho$ approaches 1, common $\rho$-belief approximates common knowledge. ${ }^{24}$ This line of reasoning further suggests, if only loosely, that not only are agents' success at coordinating their strategies dependent on the beliefs they hold about each others' beliefs, but that the more well-founded these beliefs are, the better they are able to coordinate strategies. This brings us directly to leadership, for one role of leadership is to influence how well founded agents think certain beliefs are.

\section{Leadership and Coordination}

For the purposes of this paper, leadership has been defined as the taking of actions that coordinate the complementary actions of many people through the creation of belief conditions that (at least) substitute for common knowledge, and where these actions characteristically consists of some act of communication directed at those being led. It is time to make something more out of this tentative definition.

Why may coordination problems cause a need for leadership in the above sense? In order to get a take on this issue, it is convenient to make a distinction between coordination problems (represented by means of coordination games) in which common knowledge (or, at least a common $\rho$-belief where $\rho$ is close to 1 ) about pay-offs and strategies obtains initially and those in which it does not. Moreover, it is convenient to make a distinction between games where agents can communicate by exchanging cheap talk (at no or low cost) and those in which they can't (or communication is very costly). ${ }^{25}$ However, the leader will be privileged by being the only player who can always communicate if he so chooses. These distinctions produce four cases in which leadership plays different roles (table 1). They are considered seriatiam.

\section{XXXXXXXX Insert Table 1 here XXXXXXXX}

Case 1 represents the case where leadership is least likely to play a role, since knowledge is common and agents may communicate at low or no cost. If communication costs are strictly 0 , coordination will be instantaneous. However, with positive (if small) communication costs, delay is a possibility. For example, the relevant game may be a pure symmetric coordination game without any focal points (e.g., matrix 1a). In this situation, agents want to delay decisions because they first want to communicate with other agents. The incentives for delay are caused by the complementarity of actions that implies gains from coordination.

\footnotetext{
${ }^{24}$ But see Shin and Williamson (1996) for some examples where no amount of common belief (short of the maximum) will do as a substitute for common knowledge.

25 Implicitly, the cost of communication dimension captures group size.
} 
These incentives may, however, cause an inefficiency, since there is no social gain from delay (Gale 1995). In this situation, the exercise of leadership, that is, the picking of some strategy, may economize on delay and communication costs.

Case 2 differs from case 1 by not allowing agents to engage in communication. However, the common knowledge assumption is maintained. As we have seen, there is substantial empirical evidence that agents may not choose the effficient equilibrium when they cannot communicate, for example, in assurance game situations (e.g., matrix 1b), although the have full common knowledge about payoffs, strategies, and rationality. In this situation, the leader may, by playing the efficient equilibrium and making this common knowledge, induce the other player to play the efficient equilibrium.

Moreover, agents may have difficulties coordinating on an equilibrium, when their "Schelling competence" is low (i.e., there are no obvious focal points), or they have to go through complex and costly reasoning processes á la the Stackelberg heuristic of Colman and Bacharach (1997), or they have to invest in flexibility (i.e., choose several actions at the same time by incurring some costs - see Galesloot and Goyal 1997) in order to reach their preferred equilibrium. Through the signal provided by the leader picking some strategy, these coordination problems may be resolved.

Case 3 refers to the situation where knowledge is not held in common, but where agents may communicate at no or low cost. If communication costs are strictly 0 , one would expect common knowledge conditions to be established instaneously, and coordination follows in the same split second. However, if communication costs are positive, but small, there may still be a role for leadership, particularly with respect to convincing players that there are gains from coordination.

Case 4 refers to the situation where knowledge is not held in common, and where agents cannot communicate (at reasonable cost). Although theoretically extreme, this is also the most realistic of the four cases. The real world of managers and leaders is not a world of simple two-strategies, two-players coordination games with costless cheap talk and common knowledge, but rather large-scale games with, imperfect recall, state-contingent uncertainty, etc. In this situation, players are likely to have incomplete information (or none at all) about other players, available strategies, previous plays, etc., and games will have to be re-defined and played anew (Calvert 1995). In a large-scale game, individual belief formation may at most proceed from extrapolating the current aggregate behavior of the population. ${ }^{26}$ There is not likely to be an exact (if any) correspondence between players, strategies and outcomes in various "repetitions" of "the game". There will likely be multiple equilibria. In such a situation, leadership may be conceptualized as picking one equilibrium out of a multiplicity (Calvert 1992), for example, by establishing belief conditions that approximate common knowledge.

\footnotetext{
${ }^{26}$ Van Huyck et al.'s $(1990,1991)$ results clearly indicate that group size is important in determining
} the long run coordination outcome. 
To be more specific about how leadership works by influencing beliefs in the absence of common knowledge, consider Colman and Bacharach's (1997) work on "the Stackelberg heuristic," which was mentioned earlier. In their work, no player is, strictly speaking, a leader; the Stackelberg element is introduced by thinking of oneself as a Stackelberg leader. However, we may find room for more genuine leadership if we provide a realistic interpretation of the fundamental assumption in the model that any conclusion about which strategy to play reached by player $\mathrm{A}$ will be perfectly anticipated by player B, and vice versa (i.e., is common knowledge). This may make sense for small groups characterized by a long time of interaction (Camerer and Knez 1994). But in larger scale settings with less of a history of interaction, players may not have such an easy time performing the Stackelberg heuristic. ${ }^{27}$ In such situations, it may make sense to condition one's strategy choices on the choices of one particular player - who will be, in a sense, a leader.

Another example relates to the electronic mail game of Rubinstein (1989). Organizational phenomena that are akin to the electronic mail game may be represented by problems of coordinating in an administrative hierarchy: If senior management's strategic plan calls for new initiatives if certain conditions obtain and these new initiatives require inter-departmental coordination, what should division managers do (Rumelt 1995)? Moving first may be costly, but communication regarding concerted action will not lead to common knowledge. Top-management may circumvent these problems simply by ordering all division managers to show up at a particular place and date, communicate their new initiatives and make sure that all division managers publicly and explicitly agree on coordinating their actions. This may help establishing the required condition of common knowledge (or an approximation in terms of common beliefs). ${ }^{28}$

To sum up on the above, leadership may be thought of in terms of remedying 1) problems of coordinating on an equilibrium when agents are initially outside equilibrium; 2) problems of coordinating on one equilibrium out of a multitude; and 3) problems of moving from an inferior equilibrium to the efficient equilibrium by influencing the beliefs that agents hold. The question then arises how the leader accomplishes this and what motivates his followers to follow him.

\section{Leadership, Knowledge, and Communication}

The story that has been sketched in the preceding pages relies heavily on the notion of common knowledge (or at least common $\rho$-belief with a high $\rho$ ). However, it has already been noted that common knowledge may be an unrealistic

\footnotetext{
27 Also, the Stackelberg heuristic will obviously not be helpful to players that are caught in symmetric coordination games.

${ }^{28}$ Polanyi (1958) provides a further illustration of the link between belief dynamics and leadership. As he points out (1958: 224), submitting to leadership may itself be a coordination problem: "If, in a group of men each believes that all the others will obey the commands of a person claiming to be their common superior, all will obey this person as their superior ... [A]ll are forced to obey by the mere supposition of the others' continued obedience, without any voluntary support being given to the superior by any member of the group."
} 
assumption, because we, strictly speaking, can never be absolutely certain that something is common knowledge. One may conclude that in interaction we will always suffer from the inefficiencies illustrated by Rubinstein's (1989) electronic mail game. However, such a conclusion is premature.

One interpretation of the notion of common knowledge is to not actually think of it as involving conscious ever-ascending processes of reasoning, but rather as something that players recognize heuristically, somewhat akin to Monderer and Samet's (1989) notion of common $\rho$-belief. For example, if players have a long history of interaction, this may be sufficient to allow them to shortcut the infinite processes of reasoning involved in the common knowledge assumption. For example, from the observed body language of the other players or through eye contact, etc., they may conclude on the basis of their earlier history of interaction that common knowledge is being formed (or, $\rho$ is approaching 1). They simply know. Hence, the importance of face to face contact in the examples with which I began this paper. Other social practices in firms - notably various kinds of social gatherings in which management typically insists that a substantial part of employees be present - may play a similar role: They are mechanisms for installing common knowledge among employees. For example, they may help to build up the "precedents" (Knez 1998) that Kreps' (1990) analyzes as an important part of corporate culture, and which means that all employees know that everybody knows that in situations of type $x$, the thing to do is $y .{ }^{29}$

\section{Judgment, Motivation and Commitment}

So far, I have tacitly assumed that the leader is a sort of benevolent deus ex machina, who spots and resolves coordination problems to the benefit of all concerned. This raises a number of problems that so far have been sidestepped. The first problem relates to the informational advantage of leaders, the second relates to the leader's motivation for leading, and the third relates to how he secures that those he wants to lead actually follow him.

With respect to the first issue, Hermalin (1998) begins his analysis by assuming that the leader already has some informational advantage. The ability to glimpse or intuitively judge what is the "true" structure of a situation (say, an ongoing battle) and take action on the basis of that judgment is a common interpretation (perhaps rather definition) of successful leadership. It is, however, not clear that traditional social science has much to contribute to the understanding of the cognitive and psychological issues of what makes the leader's judgment superior to other players' judgment or, conversely, why leaders sometimes fail in their judgment of a situation. ${ }^{30}$ However, it is certainly possible to address a number of issues that are connected to the exercise of judgment, such as the

\footnotetext{
${ }^{29}$ In turn, this suggests that leadership and a well-established corporate culture may be substitutes with respect to the solution to certain coordination problems. However, there may also be complementary relations between them, as, for example, a strong corporate culture may ease the exercise of leadership, and leadership may help to build up corporate culture.

30 Although psychology-based behavioral research may be helpful here.
} 
consequences of the exercise of judgment and the motivation of leaders and followers.

With respect to the motivation of the leader we may well make standard assumptions with respect to his behavior. As portrayed so far, the leader's activities create additional utility for the relevant players by; by making players change their strategies, he moves them towards better equilibria. He can be paid out of this extra value, or, if he is one of the players in the game himself, we will automatically gain from his activities (supposing the relevant games are coordination games such as those in matrices 1a-1c).

With respect to the issue of how to motivate followers to actually follow, things are slightly more complicated. As discussed so far, leadership consists in influencing beliefs so that better equilibria can be reached, for example, through explicit (speech acts) and more tacit (body language) communication and through "leading by example" by being the first to pick a certain strategy. That the issues of communication and commitment are closed linked has often been pointed out. Thus, Kotter, an expert on leadership, argues that “... people will not make sacrifices ... unless they think that the potential benefits of change are attractive and unless they really believe that transformation is possible. Without credible communication, and a lot of it, employees' minds and hearts are never captured" (Kotter 1996: 9). In the way that Kotter uses the concept here, "credible communication" corresponds closely to the point that leaders may be instrumental in installing common knowledge conditions among players. Thus, if everybody believe that everybody else will move to a superior equilibrium when such as change has been communicated by the leader, and if it is common knowledge that players condition their behavior on the leader and that the leader himself gains by the change, then the leader's communication is very credible indeed. To put in simpler terms, in pure coordination games, we would clearly expect "cheap talk" to be credible, since it is clearly in the interest of the announcing player to follow what he himself announces.

\section{Application and Evidence?}

The primary aim of this paper has been to put forward a conceptualization of leadership that while based on simple game theoretical ideas can capture much of what is meant by leadership from a cognitive or symbolic perspective, and goes some way towards rationalizing such a notion. The ideas here should first and foremost be judged relative to how well they make sense out of cognitive and symbolic understandings of leadership, and of existing business practice.

With respect to the latter issue, Camerer and Knez (1996) have suggested that Total Quality Management may play a role akin to the role that this paper has ascribed to leadership, namely to help establish focal points that ease coordination of actions. Kreps (1990) argue much the same with respect to corporate culture. That perspective may be generalized, drawing on the ideas of this paper. Thus, the currently highly fashionable emphasis on "knowledge management" may be interpreted as an attempt to create knowledge conditions among employees that 
approximate common knowledge. In such an interpretation the practice of knowledge management - which may roughly be interpreted as a practice of disseminating and sharing knowledge that was hitherto more asymmetrically distributed - is useful, not because it disseminates valuable knowledge per se, but rather because the process of knowledge management is a vehicle for establishing knowledge conditions that more closely resemble those of common knowledge. Thus, knowledge-intensive organizations engage in knowledge management projects, not (just) because this allows for more efficient use of the knowledge that is available to the organization, but because these firms typically have a coordination need (e.g., because employees are hard-to-monitor professionals, organization structures are flat) that cannot easily be resolved by means of existing hierarchical mechanisms. Establishing common knowledge conditions helps here. A similar argument may be applied to the emphasis in some quarters of the strategy literature on "vision" (e.g., Prahalad and Hamel 1994). Thus, the value of vision may lie not so much in its entrepreneurship (i.e., identifying new business opportunities), but rather in the contribution to the establishment of common knowledge conditions that a simple and effectively communicated vision may bring.

Existing experimental evidence to has a bearing, directly or indirectly, under the issues under consideration here. For example, it is a rather robust result that coordination on the efficient equilibrium in weakest-link games is virtually impossible for groups the size of 10 persons or more (Van Huyck, Battalio and Beil 1990; Camerer and Knez 1994). Of course, this doesn't prove the need for leadership, but it does suggest that various institutions, and among them leadership, exist for the purpose of building assurance. One device that for a wide class of games improves coordination - both in theory and in experiments - is communication (Farrell 1987, 1988; Cooper, DeJong, Forsythe and Ross 1989, 1992, 1994), and communication and leadership has indeed been connected in this paper.

However, there is reason to be cautious here, for communication is not always helpful. Thus, Weber, Camerer, Rottenstreich and Knez (1998) conducted experiments with weakest-link games and found that letting one member of a large group partake of the role of a speaker and engage in brief one-way, pre-play communication did not improve the success with which the group coordinated. It may of course be objected that weakest-link games are extreme games (they are very risky) in a broad class of coordination games and that the experimental subjects that were picked as speaker/leaders were inexperienced students, not real managers. However, the results of Weber et al. (1998) do indicate that communication is not necessarily effective across the board and that in some interaction situations, communicative leadership will have to be backed up with other means that can further build assurance (cf. Kotter 1996).

Moreover, recent experimental work has begun to discern some basic mistakes that leaders may be prone to committing. Thus, Weber (1998) investigated the dependence of successful coordination in weakest-link games (generalized assurance games) on the size of the group that played the game. His results 
indicate that starting with small groups and then "growing" them at a slow rate (corresponding to "controlled growth" in firms) led to successful coordination in large group, whereas successful coordination was impossible if the size of the group was initially large. Weber then allowed for the possibility that one of the players may become a "leader" in the sense that he is allowed to determine the growth path of group size. The experiments suggest that leaders tend to increase group size too quickly. In other words, they tend to not have the correct cognition of the situation. Again, the easy objection is the same as above - that is, weakestlink games are extreme games in the broad class of coordination games and the experimental subjects are inexperienced students - but the result certainly do indicate the potential importance of behavioral aspects for the understanding of leadership (cf. also Heath, Knez and Camerer 1993).

\section{Conclusions}

This paper has had an explorative, yet ambitious agenda. On the overall level, it has been suggested - following the lead of Camerer and Knez (1994, 1996, 1997) - that coordination games carry important lessons for the study of organizational phenomena, including leadership in organizations. The innovation of the present paper is to suggest and sketch a notion of leadership that links up with cognitive notions of leadership - in which the "inculcation of beliefs" is central —, but which is founded on a rational choice methodology and draws upon simple ideas in game theory. Thus, the paper suggests that leadership is an important member of the set of institutions for resolving coordination problems; it is closely connected to issues of communication; it may arise as a response to significant communication costs in large-scale groups; leadership functions partly through communication; and leadership partakes of its coordinative role by establishing common knowledge conditions (or, belief conditions approximating this).

The aim of the present paper has primarily been to take the first step of conceptualizing the leadership phenomenon in a way that while linking up with importants strands in the leadership literatur is founded on rational choice methodology. In a field that is characterized by so much diversity and lack of clarity with respect to the nature of leadership, clear conceptualizations are crucial. However, much more work is required to refine the notion of leadership in this paper, understand its reach, and go beyond definition and conceptualization to precise propositions. Moreover, empirical work is clearly needed to obtain a better understanding of the situations where leadership in the sense defined in this paper may be less helpful (perhaps large-scale weakest-link games) and those where it performs a distinctly useful function. 


\section{References}

Aumann, Robert. 1976. “Agreeing to Disagree," The Annals of Statistics 4: 1236-1239.

Aumann, Robert and Adam Brandenburger. 1995 “Epistemic Conditions for Nash Equilibrium," Econometrica 63: 1161-1180.

Bettenhausen, Kenneth and J. Keith Murnighan. 1985. “The Emergence of Norms in Competitive Decision-Making Groups," Administrative Science Quarterly 30: 350-372.

Barnard, Chester I. 1948. The Functions of the Executive. Cambridge, MA: Harvard University Press.

Bacharach, Michael and Michele Bernasconi. 1997. "The Variable Frame Theory of Focal Points: An Experimental Study," Games and Economic Behavior 19: 1-45.

Bicchieri, Christina. 1993. Rationality and Coordination. Cambridge: Cambridge University Press.

Bikhchandani, Sushil, David Hirshleifer, and Ivo Welch. 1992. "A Theory of Fads, Fashions, Custom, and Cultural Change as Informational Cascades," Journal of Political Economy 100: 992-1026.

Binmore, Ken and Patha Dasgupta, eds. 1986. Economic Organizations as Games. Oxford: Oxford University Press.

Brickley, Jim, Cliff Smith, and Jerry Zimmerman. 1996. Organizational Architecture. Toronto: Irwin.

Bulow, Jeremy, John D. Geanakoplos and Paul D. Klemperer. 1985. "Multimarket Oligopoly: Strategic Substitutes and Complements," Journal of Political Economy 93: 488-511.

Calvert, Randall L. 1992. "Leadership and Its Basis in Problems of Social Coordination," International Political Science Review 13: 7-24.

Calvert, Randall L. 1995. "The Rational Choice Theory of Social Institutions: Cooperation, Coordination, and Communication," in Jeffrey S. Banks and Eric A. Hanushek, eds. Modern Political Economy: Old Topics, New Directions. Cambridge: Cambridge University Press.

Camerer, Colin and Marc Knez. 1994. "Creating Expectational Assets in the Laboratory: Coordination in 'Weakest-Link' Games," Strategic Management Journal 15: 101-119.

Camerer, Colin and Marc Knez. 1996. “Coordination, Organizational Boundaries and Fads in Business Practice," Industrial and Corporate Change 5: 89-112.

Camerer, Colin and Marc Knez. 1997. "Coordination in Organizations: a GameTheoretic Perspective," in Zur Shapira, ed. 1997. Organizational Decision Making. Cambridge: Cambridge University Press.

Carlsson, Sune. 1951. Executive Behavior. 1991 ed. Uppsala: Acta Universitatis Upsaliensis. 
Casson, Mark. 1994. "Why are Firms Hierarchical?," Journal of the Economics of Business 1: 47-76.

Coleman, James S. 1990. "Rational Organization," Rationality and Society 2: 94-105.

Colman, Andrew M. 1997. "Salience and Focusing in Pure Coordination Games," Journal of Economic Methodology 4: 61-81.

Colman, Andrew M. and Michael Bacharach. 1997. "Pay-Off Dominance and the Stackelberg Heuristic," Theory and Decision 43: 1-19.

Colman, Andrew M. and Jonathan A. Stirk. 1998. "Stackelberg Reasoning in Mixed-Motive Games: An Experimental Investigation," Journal of Economic Psychology 19: 279- 293.

Conger, Jay A. and Rabindra N. Kanungo. 1998. Charismatic Leadership in Organizations. London: SAGE Publications.

Cooper, Russell W. 1999. Coordination Games: Complementarities and Macroeconomics. Cambridge: Cambridge University Press.

Cooper, Russell W. and Andrew John. 1988. "Coordinating Coordination Failures in Keynesian Models," Quarterly Journal of Economics 103: 441-463.

Cooper, Russell W., Douglass V. DeJong, Robert Forsythe and Thomas Ross. 1989. "Communication in the Battle of the Sexes Game: Some Experimental Results," RAND Journal of Economics 20: 568-587.

Cooper, Russell W., Douglass V. DeJong, Robert Forsythe and Thomas Ross. 1992. "Communication in Coordination Games," Quarterly Journal of Economics 107: 739-771.

Cooper, Russell W., Douglass V. DeJong, Robert Forsythe and Thomas Ross. 1994. "Alternative Institutions for Resolving Coordination Problems: Experimental Evidence on Forward Induction and Preplay Communication," in J. Friedman, ed. Problems of Coordination in Economic Activity, Norwell: Kluwer.

Crawford, Vincent P. and Hans Haller. 1990. "Learning How to Cooperate: Optimal Play in Repeated Coordination Games," Econometrica 58: 571-595.

Crawford, Vincent P. and Joel Sobel. 1982. "Strategic Information Transmission," Econometrica 50: 1431-1451.

Cremer, Jacques. 1990. "Common Knowledge and the Co-ordination of Economic Activities," in Masaahiko Aoki, Bo Gustafsson and Oliver E. Williamson, eds. The Firm as a Nexus of Treaties. London: Sage.

Demsetz, Harold. 1988. "The Theory of the Firm Revisited," Journal of Law, Economics, and Organization 4: 141-161.

Dupuy, Jean-Pierre. 1989. "Common Knowledge, Common Sense," Theory and Decision 27: 37-62.'

Farrell, Joseph. 1987. "Cheap Talk, Coordination, and Entry," Rand Journal of Economics 18: 34-39.

Farrell, Joseph. 1988. "Communication, Coordination, and Nash Equilibrium," Economics Letters 27: 209-214. 
Farrell, Joseph and Garth Saloner. 1985. "Standardization, Compatibility, and Innovation," Rand Journal of Economics 16: 70-83.

Field, Alexander. 1984. "Microeconomics, Norms, and Rationality," Economic Development and Cultural Change 32: 683-711.

Foss, Nicolai J. 1996. "Knowledge-Based Approaches to the Theory of the Firm: Some Critical Comments". Organization Science 7: 470-476.

Foss, Kirsten and Nicolai J Foss. 2000. "Theoretical Isolation in Contract Economics," forthcoming in Journal of Economic Methodology.

Frey, Bruno. 1997. Not Just for the Money: An Economic Theory of Personal Motivation. Aldershot: Edward Elgar.

Friedman, James W., ed. 1994. Problems of Coordination in Economic Activity. Boston: Kluwer.

Frohlich, Norman, Joe A. Oppenheimer, and Oran R. Young. 1971. Political Leadership and Collective Goods. Princeton: Princeton University Press.

Fudenberg, Drew and Jean Tirole. 1995. Game Theory. Cambridge, MA: The MIT Press.

Galbraith, Jay R. 1973. Designing Complex Organizations. Reading, MA: AddisonWesley.

Gale, Douglas. 1995. “Dynamic Coordination Games," Economic Theory 5: 1-18.

Galesloot, Bob M. and Sanjeev Goyal. 1997. "Costs of Flexibility and Equilibrium Selection," Journal of Mathematical Economics 28: 249-264.

Gardner, John. 1990. On Leadership. New York: The Free Press.

Geanakoplos, John. 1992. "Common Knowledge," Journal of Economic Perspectives 6: 53-82.

Gilbert, Margaret. 1992. On Social Facts. Princeton: Princeton University Press.

Greenan, Nathalie and Dominique Guellec. 1994. "Coordination Within the Firm and Endogenous Growth," Industrial and Corporate Change 3: 173-196.

Grossman, Sanford, and Oliver Hart. 1986. "The Costs and Benefits of Ownership: A Theory of Vertical Integration," Journal of Political Economy 94: 691-719.

Harsanyi, John and Reinhard Selten. 1988. A General Theory of Equilibrium Selection in Games. Cambridge: MIT Press.

Hardin, Russell. 1982. Collective Action. Baltimore: John Hopkins University Press.

Hart, Oliver. 1995. Firms, Contracts, and Financial Structure. Oxford: Oxford University Press.

Hayek, Friedrich A. 1937. "Economics and Knowledge" in idem. 1948. Individualism and Economic Order. Chicago: University of Chicago Press.

Heath, Chip, Marc Knez, and Colin Camerer. 1993. "The Strategic Management of the Entitlement Process in the Employment Relationship," Strategic Management Journal 14: 75-93.

Hermalin, Benjamin. 1998. “Toward an Economic Theory of Leadership: Leading by Example," American Economic Review 88: 1188-1206. 
Holmström, Bengt. 1982. "Moral Hazard in Teams," Bell Journal of Economics 13: 324-340.

Holmström, Bengt. 1999. "The Firm as a Subeconomy," Journal of Law, Economics, and Organization 15: 74-102.

House, Robert J. and Mary L. Baetz. 1979. "Leadership: Some Empirical Generalizations and New Research Directions," Research in Organizational Behavior 1: 341-423.

Knez, Mark and Colin Camerer. 1994. "Creating Expectational Assets in the Laboratory: Coordination in 'Weakest-Link' Games," Strategic Management Journal 15: 101-119.

Kotter, John. 1996. Leading Change. Boston: Harvard Business School Press.

Knez, Mark. 1998. "Precedent Transfer in Experimental Conflict-of-Interest Games," Journal of Economic Behavior and Organization 34: 239-249.

Kramarz, F. 1996. "Dynamic Focal Points in N-Person Coordination Games," Theory and Decision 40: 277-313.

Kreps, David M. 1990a. "Corporate Culture and Economic Theory," in James Alt and Kenneth Shepsle, eds. Positive Political Economy. Cambridge: Cambridge University Press.

Kreps, David M. 1990b. Game Theory and Economic Modelling. Oxford: Oxford University Press.

Langlois, Richard N. 1998. "Personal Capitalism as Charismatic Authority: The Organizational Economics of a Weberian Concept," Industrial and Corporate Change 7: 195-214.

Langlois, Richard N. and Nicolai J. Foss. 1999. "Capabilities and Governance: the Rebirth of Production in the Theory of the Firm," KYKLOS 52: 201-218 .

Lewis, David. 1969. Convention: A Philosophical Study. Cambridge, MA: Harvard University Press.

Loasby, Brian J. 1995. "Running a Business: An Appraisal of Economics, Organization and Management by Paul Milgrom and John Roberts," Industrial and Corporate Change 4: 471-489.

Luce, R. Duncan and Howard Raiffa. 1957. Games and Decisions. New York: John Wiley \& Sons.

Mailath, George J. 1998. “Do People Play Nash Equilibrium? Lessons From Evolutionary Game Theory," Journal of Economic Literature 36: 1347-1374.

Malone, Thomas W. and Kevin Crowston. 1994. "The Interdisciplinary Study of Coordination," ACM Computing Surveys 26: 87-119.

Milgrom, Paul and John Roberts. 1992. Economics, Organization, and Management. Englewood-Cliffs: Prentice Hall.

Mintzberg, Henry. 1973. The Nature of Managerial Work. Englewood Cliffs: PrenticeHall.

Monderer, Dov and Dov Samet. 1989. “Approximating Common Knowledge With Common Beliefs," Games and Economic Behavior 1: 170-190. 
Murnighan, J. Keith. 1994. “Game Theory and Organizational Behavior," Research in Organizational Behavior 16: 83-123.

Nash, John. 1951. “Non-Cooperative Games," Annals of Mathematics 54: 286-295.

Neumann, John von and Oskar Morgenstern. 1944. Theory of Games and Economic Behavior. Princeton: Princeton University Press.

Ojha, Abhoy K., John L. Brown and Nelson Philips. 1997. "Change and Revolutionary Change: Formalizing and Extending the Punctuated Equilibrium Paradigm," Computational and Mathematical Organization Theory 3: 91-111.

Pierce, Jon L. and John W. Newstrom, eds. 2000. Leaders and the Leadership Process. Boston: Irwin.

Polanyi, Michael. 1958. Personal Knowledge. London: Routledge and Kegan Paul.

Powell, Walter W. and Paul J. DiMaggio (eds.). 1991. The New Institutionalism in Organizational Analysis, Chicago: Chicago University Press.

Prahalad, C.K. and Gary Hamel. 1994. Competing for the Future. New York: Free Press.

Rabin, Matthew. 1990. “Communication Between Rational Agents," Journal of Economic Theory 51: 144-170.

Rabin, Matthew. 1993. "Incorporating Fairness into Game Theory and Economics," American Economic Review 83: 1281-1302.

Radner, Roy. 1996. "Bounded Rationality, Indeterminacy, and the Theory of the Firm," Economic Journal 106: 1360-1373.

Richardson, George B. 1960. Information and Investment. Oxford: Oxford University Press.

Rost, John. 1991. Leadership for the Twenty-First Century. New York: Praeger.

Rotemberg, Julio J. and Garth Saloner. 1993. "Leadership Style and Incentives," Management Science 39: 1299-1318.

Rubinstein, Ariel. 1989. “The Electronic Mail Game: Strategic Behavior under 'Almost Common Knowledge'," American Economic Review 79: 385-391.

Rumelt, Richard P. 1995. "Inertia and Transformation," in Cynthia A. Montgomery, ed. 1995. Evolutionary and Resource-Based Theories of the Firm. Boston: Kluwer.

Salanié, Bernard. 1997. The Economics of Contracts. Cambridge, Mass.: MIT Press.

Schelling, Thomas. 1960. The Strategy of Conflict. Cambridge, MA: Harvard University Press.

Schelling, Thomas. 1978. Micro-motives and Macro-Behaviour. New York: The Free Press.

Schotter, Andrew. 1981. The Economic Theory of Social Institutions. Cambridge: Cambridge University Press.

Selznick, Philip. 1957. Leadership in Administration. Evanston, Ill.: Row \& Peterson. 
Shin, Hyun Song and Timothy Williamson. 1996. "How Much Belief is Necessary for a Convention?," Games and Economic Behavior 13: 252-268.

Shleifer, Andrei and Lawrence Summers. 1990. "Breach of Trust in Corporate Takeovers," in Alan Auerbach, ed. Corporate Takeovers: Causes and Consequences. Chicago: University of Chicago Press.

Sugden, Robert. 1995. "A Theory of Focal Points," The Economic Journal 105: 533550.

Thompson, James D. 1967. Organizations in Action. New York: McGraw-Hill.

van Huyck, J.B., R.C. Battalio, and R.O. Beil. 1990. "Tacit Coordination Games, Strategic Uncertainty, and Coordination Failure," American Economic Review 80: 234-248.

van Huyck, J.B., R.C. Battalio, and R.O. Beil. 1991. "Strategic Uncertainty, Equilibrium Selection, and Cooordination Failure in Average Opinion Games," Quarterly Journal of Economics 106: 885-910.

Vechhio, Robert P., ed. 1997. Leadership: Understanding the Dynamics of Power and Influence in Organizations. Notre Dame: University of Notre Dame.

Weber, Roberto. 1998. “Coordination Problems in Growing Firms: Insights From Experiments," Manuscript.

Weber, Roberto, Colin Camerer, Y. Rottenstreich, and Mark Knez. 1998. "The Illusion of Leadership: Misattribution of Cause in Coordination Games," Manuscript.

Williamson, Oliver E. 1985. The Economic Institutions of Capitalism. New York: The Free Press.

Williamson, Oliver E. 1996. The Mechanisms of Governance. Oxford: Oxford University Press.

Williamson, Oliver E. 1998. "Human Actors and Economic Organization," paper for the 1998 ISNIE meeting, Paris, September 16-17.

Witt, Ulrich. 1997. “'Lock-In' vs. 'Critical Masses' - Industrial Change Under Network Externalities," International Journal of Industrial Organization 15: 753773.

Young, H. Peyton. 1996. "The Economics of Convention," Journal of Economic Perspectives 10: 105-122. 
Table 1

The role of leadership under alternative assumptions about common knowledge and communication

\begin{tabular}{|c|c|c|c|}
\hline \multirow{5}{*}{$\begin{array}{l}\text { Coordi- } \\
\text { nation } \\
\text { games }\end{array}$} & \multirow{3}{*}{$\begin{array}{l}\text { With } \\
\text { CK }\end{array}$} & \multicolumn{2}{|r|}{ The Role of Leadership } \\
\hline & & $\begin{array}{l}\text { With } \\
\text { communi- } \\
\text { cation }\end{array}$ & $\begin{array}{l}\text { Case 1: Leadership may economize on delay and } \\
\text { communication costs, particularly in many players } \\
\text { situations. }\end{array}$ \\
\hline & & $\begin{array}{l}\text { Without } \\
\text { communi- } \\
\text { cation }\end{array}$ & $\begin{array}{l}\text { Case 2: Leadership may be required when "Schelling } \\
\text { competence" is low, and/or there is coordination failure } \\
\text { because agents avoid the risky, but efficient equilibrium; } \\
\text { and/or agents have to go through complex and costly } \\
\text { reasoning processes in order to reach their preferred } \\
\text { equilibrium. E.g., leaders may "build assurance" in } \\
\text { assurance game situations. }\end{array}$ \\
\hline & $\begin{array}{l}\text { Without } \\
\text { CK }\end{array}$ & $\begin{array}{l}\text { With } \\
\text { communi- } \\
\text { cation }\end{array}$ & $\begin{array}{l}\text { Case 3: Leadership economizes on the communication } \\
\text { costs of establishing common knowledge conditions. E.g., } \\
\text { the leader may help convincing players that there are } \\
\text { gains from coordination. }\end{array}$ \\
\hline & & $\begin{array}{l}\text { Without } \\
\text { communi- } \\
\text { cation }\end{array}$ & $\begin{array}{l}\text { Case 4: Leadership helps establishing common knowledge } \\
\text { conditions by influencing beliefs, or chooses one } \\
\text { equilibrium out of a multiplicity. }\end{array}$ \\
\hline
\end{tabular}


Figure 1: Coordination games

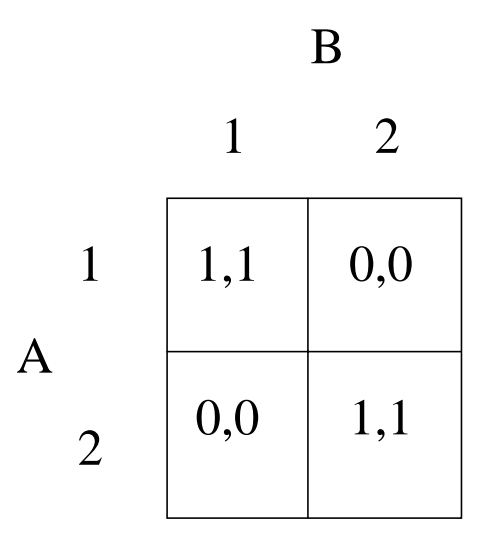

1a: Symmetric

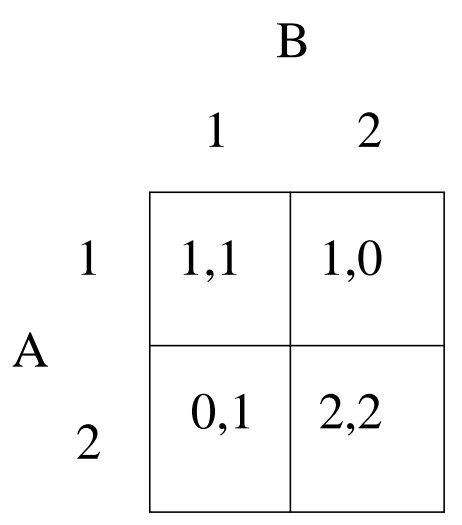

1b: Assurance

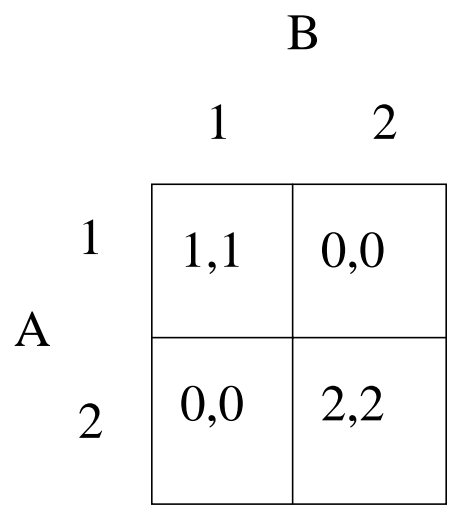

1c: Asymmetric 
